\title{
Penerapan Metode Fast Persediaan Barang Pada Toko Katie Pet Shop Kota Sukabumi
}

\author{
Yusti Farlina $^{1}$, Desi Susilawati ${ }^{2}$, Tya Septiani Nurfauzia Koeswara ${ }^{3}$ \\ 1,2,3 Universitas Bina Sarana Infromatika \\ e-mail: 1yusti.yfa@bsi.ac.id, ${ }^{2}$ desi.dlu@bsi.ac.id, 3tya.tsf@bsi.ac.id
}

\begin{abstract}
Abstraksi
Peranan komputer sangat diperlukan, baik di instansi maupun perusahaan. Kemampuan komputer dalam melakukan pengolahan perhitungan persediaan stok barang serta penyimpanan data membuat banyak perusahaan memanfaatkannya untuk keperluan pengolahan data. Toko Katie Pet Shop dalam pengelolaan data persediaan barang masih secara konvensional. Toko Katie Pet Shop ini menjual berbagai macam barang atau produk perlengkapan hewan. Masalah yang terdapat pada proses pencatatan barang yang masih dilakukan secara manual dan masih menggunakan buku stok barang sebagai alat bantu dan kerap terjadi kehilangan data barang dan keterlambatan dalam penyusunan persediaan barang. Pencatatan stok barang yang dikelola terkadang tidak sesuai dengan bukti fisik yang ada. Aplikasi berbasis website dalam proses pencatatan persediaan barang pada Toko Katie Pet Shop menggunakan metode Framework for the Application of System Thinking (FAST) memiliki banyak kelebihan antara lain kemampuan untuk mendukung pengembangan aplikasi yang baik serta didukung oleh teknik yang lain. Selain itu memudahkan bagian administrator dalam proses pengelolaan data stok barang.

Kata Kunci : Metode FAST, Persediaan, Stok, Barang
\end{abstract}

\begin{abstract}
The role of computers is indispensable, both in agencies and companies. The ability of computers to process inventory calculations for inventory and data storage has made many companies use them for data processing purposes. Katie Pet Shop in managing inventory data is still conventional. This Katie Pet Shop sells various kinds of animal goods or products. Problems that exist in the process of recording goods are still done manually and still use the stock book as a tool and there is often loss of data on goods and delays in preparing inventory. The recording of the stock of goods that is managed sometimes does not match the existing physical evidence. Website-based applications in the process of recording inventory at Katie Pet Shop using the Framework for the Application of System Thinking (FAST) method have many advantages including the ability to support good application development and are supported by other techniques. In addition, it facilitates the administration in the process of managing stock data.
\end{abstract}

Keywords: FAST Method, Inventory, Stock, Goods

\section{Pendahuluan}

Teknologi informasi saat ini berdampak sangat besar bagi dunia bisnis. Selain itu juga, berdampak dalam segala aspek kehidupan. Dengan adanya perkembangan teknologi informasi ini, berguna untuk meningkatkan efektivitas, produktivitas dan daya saing (Priskila, 2018). Teknologi informasi yang digunakan menerapkan teknologi komputer untuk pengolahan data (Oktaviani, Widiarta, \& Nurlaily, 2019). Media informasi yang sangat efektif dalam menyajikan informasi, dengan kemajuan teknologi yang semakin pesat menggunakan teknologi berbasis website. Kecepatan dalam mendapatkan informasi, kemudahan transaksi serta fleksibilitas dalam mendapatkan informasi merupakan keunggulan dari teknologi sistem informasi yang saat ini berkembang dengan sangat pesat (Abdullah, Setiawan, \& Ummi, 2013). Untuk membantu dalam melakukan pekerjaan dan penyampaian informasi (Junaidi \& Sumirat, 2018). Peranan komputer sangat diperlukan, baik instansi maupun perusahaan. Kemampuan komputer dalam melakukan pengolahan perhitungan serta penyimpanan data membuat banyak perusahaan memanfaatkannya untuk keperluan pengolahan data (Hakim, Sakuroh, \& Awaludin, 2019). 
Toko Katie Pet Shop dalam pengelolaan data persediaan barang masih secara konvensional. Toko Katie Pet Shop ini menjual berbagai macam barang atau produk perlengkapan hewan. Masalah yang terdapat pada proses pencatatan barang yang masih dilakukan secara manual dan masih menggunakan buku stok barang sebagai alat bantu dan kerap terjadi kehilangan data barang dan keterlambatan dalam penyusunan persediaan barang (Fatmawati \& Munajat, 2018). Pencatatan stok barang masih dihitung manual menyebabkan perbedaan antara persediaan di catatan dengan fisik yang ada (Hasanudin, 2018). Untuk menghindari kesalahan dalam pencatatan dan pengelolaan barang maka dibuatkan sebuah aplikasi berbasis website guna memberikan kemudahan dalam proses pencatatan persediaan barang.

Sistem informasi berbasis website yang dibangun akan mudah diakses kapanpun saat dibutuhkan dengan adanya jaringan internet (Cahyana, Yuwono, \& Asmoro, 2012). Aplikasi persediaan barang berbasis website yang akan diterapkan pada Toko Katie Pet Shop menggunakan metode Framework for the Application of System Thinking (FAST) memiliki banyak kelebihan antara lain kemampuan untuk mendukung pengembangan aplikasi yang baik serta didukung oleh teknik yang lain (Halim, 2020). Metode FAST dilakukan secara berurutan yakni melalui tahapan investigasi atau survei awal, analisis masalah, analisis kebutuhan, analisis keputusan, pembuatan rancangan, mengkonstruksi, menerapkan sistem, mengoperasikan dan pemeliharaan sistem (Elsera, 2018).

Tujuan dari penelitian ini adalah untuk merancang sebuah aplikasi persediaan stok barang berbasis web sebagai solusi permasalahan yang ada di Toko Katie Shop. Dengan membuat sistem yang terkomputerisasi, diharapkan pengelolaan persediaan barang menjadi lebih efektif dan efisien.

\section{Metode Penelitian}

Metode FAST (Framework for the Application System Thinking) terdiri dari fasefase Scope Definition, Problem Analysis, Requirements Analysis, Logical Design dan Physical Design (Sari \& Nuari, 2017):

1. Scope Definition

Tahap ini merupakan langkah awal dalam proses perancangan system informasi persediaan stok barang. Dalam tahap scope definition didefinisikan ruang lingkup dari sistem informasi persediaan barang pada Toko Katie Pet Shop.

2. Problem Analysis

Analisa masalah dilakukan untuk mendefinisikan ruang lingkup dan masalah yang dihadapi dalam pengembangan sistem informasi persediaan barang.

3. Requirement Analysis

Analisa kebutuhan adalah menentukan kebutuhan sistem apa saja yang dibutuhkan pada sistem informasi persediaan barang, yaitu kebutuhan pengguna dan kebutuhan sistem untuk pembuatan aplikasi persediaan barang.

4. Logical Design

Metode perancangan yang menggunakan metode perancangan berorientasi objek dengan menggunakan UML (Unifed Modelling Language) sebagai alat bantu perancangan aplikasi persediaan stok barang.

5. Physical Design

Merupakan tahapan menterjemahkan logical design ke dalam bentuk fisik suatu aplikasi, meliputi perancangan user interface dan detail design dalam pembuatan aplikasi persediaan stok barang.

\section{Hasil dan Pembahasan \\ 3.1. Scope Definition}

Aplikasi website persediaan stok barang pada Toko Katie Shop memiliki halaman administrator. Pada halaman administrator terdapat menu login administrator, halaman beranda, halaman master, halaman transaksi, halaman laporan. Untuk halaman master terdiri dari halaman menu barang dan halaman menu supplier. Sementara untuk halaman transaksi terdiri dari halaman menu barang masuk dan halaman menu barang keluar. Pada halaman ini, bagian administrator dapat melakukan penambahan data barang, merubah data barang, menghapus data barang, melakukan penambahan data supplier, merubah data supplier, menghapus data supplier, menghapus data barang masuk, menghapus data barang keluar, membuat laporan data persediaan barang.

\subsection{Problem Analysis}

a. Pencatatan persediaan stok barang masih dilakukan secara konvensional dengan cara menuliskan di buku stok barang. 
b. Tidak sesuainya data stok barang dengan barang fisik yang ada.

c. Pencarian data barang memerlukan waktu yang lama dikarenakan harus mencari dari arsip data barang.

d. Pencatatan barang masuk dan barang keluar tidak sesuai, menyebabkan jumlah barang tidak sama.

e. Dalam pembuatan laporan persediaan stok barang memerlukan waktu yang lama dikarenakan harus disesuaikan terlebih dahulu dengan arsip data barang dan fisik.

f. Pengecekan barang memerlukan waktu lama karena harus mengecek data di buku persediaan barang.

\subsection{Requirement Analysis}

A. Aktor

Aktor yang terlibat dalam pengelolaan aplikasi persediaan barang pada Toko Katie Pet Shop yaitu hanya bagian administrator yang merupakan user dengan dapat mengakses semua menu halaman yang ada pada website.

B. Analisa Kebutuhan Pengguna

Analisa kebutuhan pengguna dalam aplikasi pengelolaan persediaan data barang meliputi:

1) Administrator dapat login, dengan username dan password

2) Administrator dapat melihat home

3) Administrator dapat mengelola data master yang terdiri dari data barang dan data supplier.

4) Administrator dapat mengelola data transaksi yaitu data barang masuk dan data barang keluar.

5) Administrator juga bisa melihat laporan persediaan barang dengan memilih jenis laporan dan tanggal laporan.

\section{Analisa Kebutuhan Sistem}

Analisa kebutuhan sistem dalam aplikasi pengelolaan persediaan data barang yaitu menyediakan hak akses untuk bagian administrator dengan mengakses halaman login. Menyediakan form untuk mengakses halaman data master, halaman data transaksi, dan halaman laporan.

D. Spesifikasi Sistem Komputer

Spesifikasi sistem komputer yang digunakan adalah:
Tabel 1. Spesifikasi Perangkat Keras

\begin{tabular}{|l|l|}
\hline $\begin{array}{c}\text { Nama } \\
\text { Perangkat }\end{array}$ & \multicolumn{1}{c|}{ Server } \\
\hline CPU & \begin{tabular}{l} 
a. $\begin{array}{l}\text { Processor Core 2 Duo } \\
\text { b. Memori RAM 2GB } \\
\text { DDR2 } \\
\text { C. }\end{array}$ \\
\hline Hard Disk 500 GB
\end{tabular} \\
\hline Keyboard & Optical Mouse/Touch Pad \\
\hline Monitor & $\begin{array}{l}\text { Layar 10" dengan resolusi } \\
\text { layar minimum 1024x768 }\end{array}$ \\
\hline $\begin{array}{l}\text { Koneksi } \\
\text { Internet }\end{array}$ & Kecepatan 1 Mbps. \\
\hline
\end{tabular}

Tabel 2. Spesifikasi Perangkat Lunak

\begin{tabular}{|l|l|}
\hline \multicolumn{1}{|c|}{$\begin{array}{c}\text { Nama } \\
\text { Perangkat }\end{array}$} & \multicolumn{1}{|c|}{ Server } \\
\hline $\begin{array}{l}\text { Sistem } \\
\text { Operasi }\end{array}$ & Windows 7 \\
\hline Web Server & Xampp \\
\hline Web Browser & $\begin{array}{l}\text { Mozilla Firefox dan } \\
\text { Google Chrome }\end{array}$ \\
\hline Text Editor & Notepad++ \\
\hline Database & MySQL \\
\hline
\end{tabular}

\subsection{Logical Design}

A. Use Case

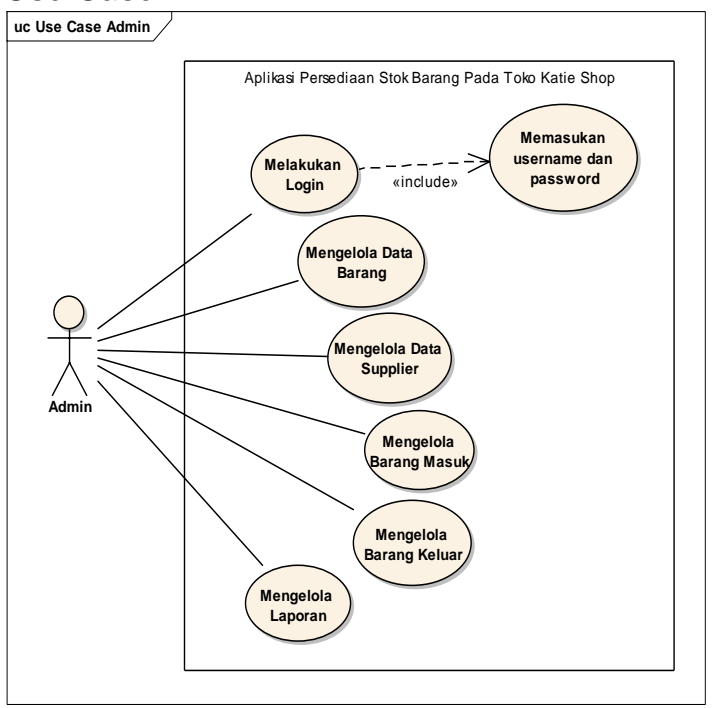

Sumber : Farlina, Susilawati, Koeswara (2021)

Gambar 1. Use Case Diagram Sistem Persediaan Barang

B. Activity Diagram

Activity Diagram bagian administrator terhadap pengelolaan data barang pada Toko Katie Pet Shop. 


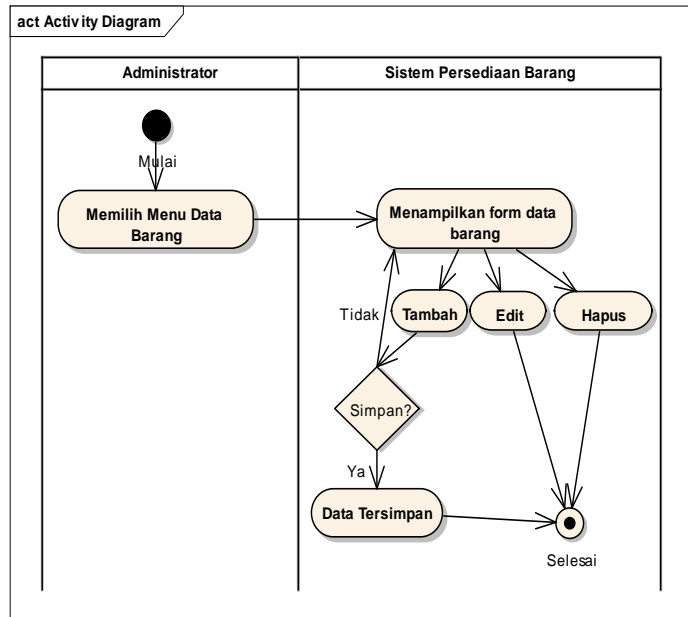

Sumber : Farlina, Susilawati, Koeswara (2021) Gambar 2. Activity Diagram Sistem Persediaan Barang
C. Sequence Diagram

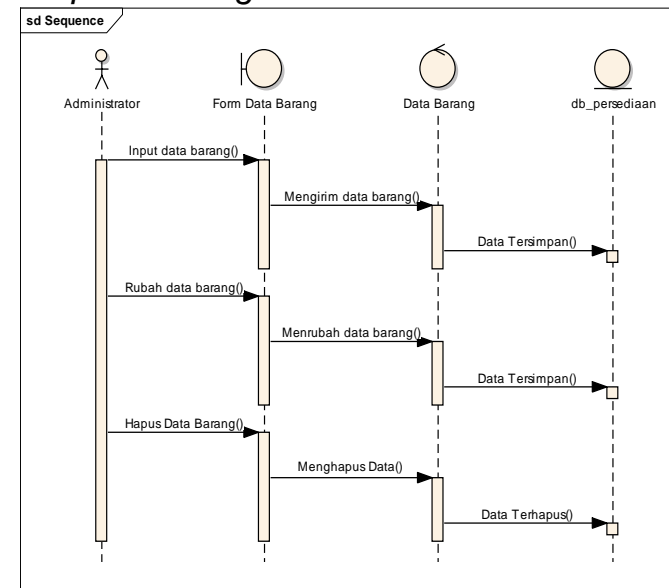

Sumber : Farlina, Susilawati, Koeswara (2021)

Gambar 3. Sequence Diagram Sistem Persediaan Barang

3.5. Physical Design

A. Rancangan ERD

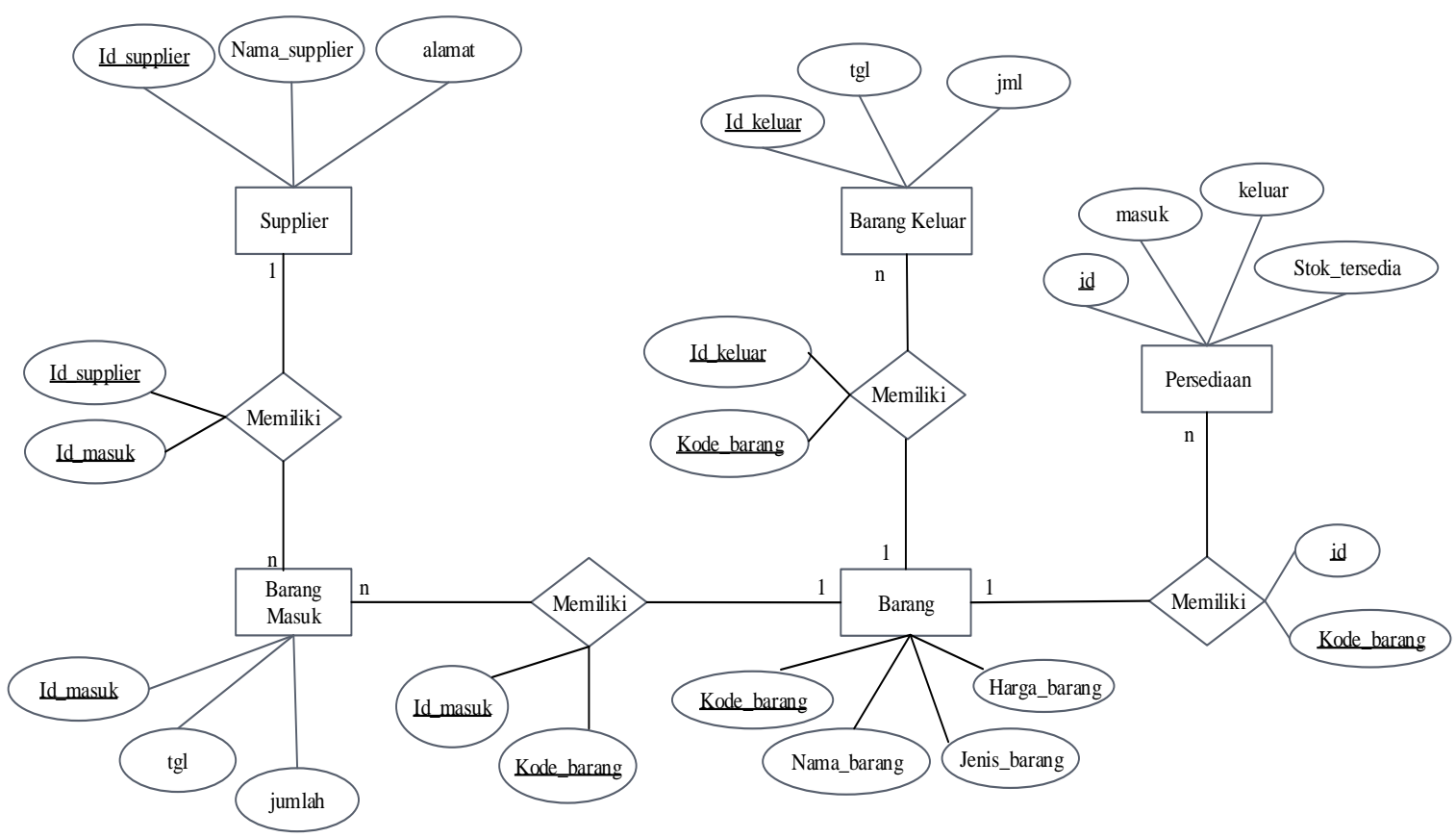

Sumber : Farlina, Susilawati, Koeswara (2021)

Gambar 4. Entity Relationship Diagram Sistem Persediaan Barang 
B. Desain Antar Muka

1. Halaman Input Barang

Halaman input barang menyediakan input data barang untuk bagian administrator. Bagian administrator bisa melakukan perubabahan data dengan menekan tombol edit, melakukan penghapusan data, dan mencari data barang dengan memasukan kode barang atau nama barang yang akan dicari.

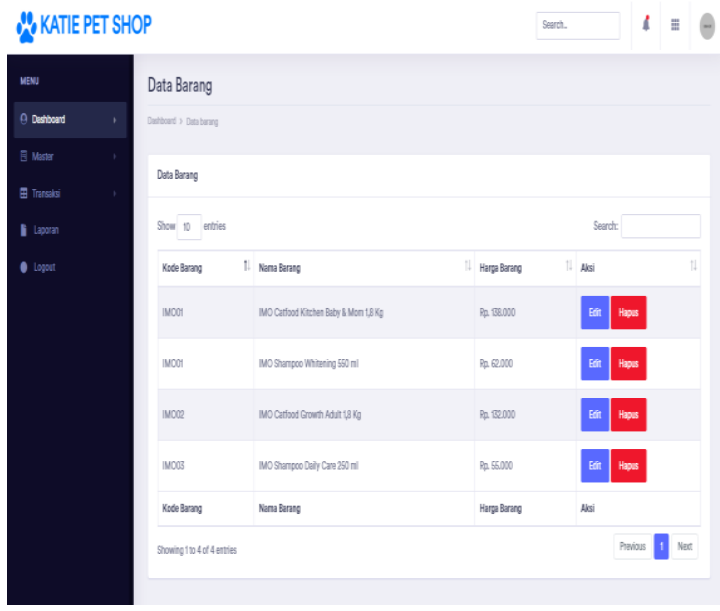

Sumber : Farlina, Susilawati, Koeswara (2021)

Gambar 5. Tampilan Input Barang

2. Halaman Input Supplier

Halaman input supplier menyediakan input data supplier untuk bagian administrator. Bagian administrator bisa melakukan perubabahan data dengan menekan tombol edit, melakukan penghapusan data, dan mencari data barang dengan memasukan id supplier atau nama supplier yang akan dicari.

MKKTTEPES SHOP
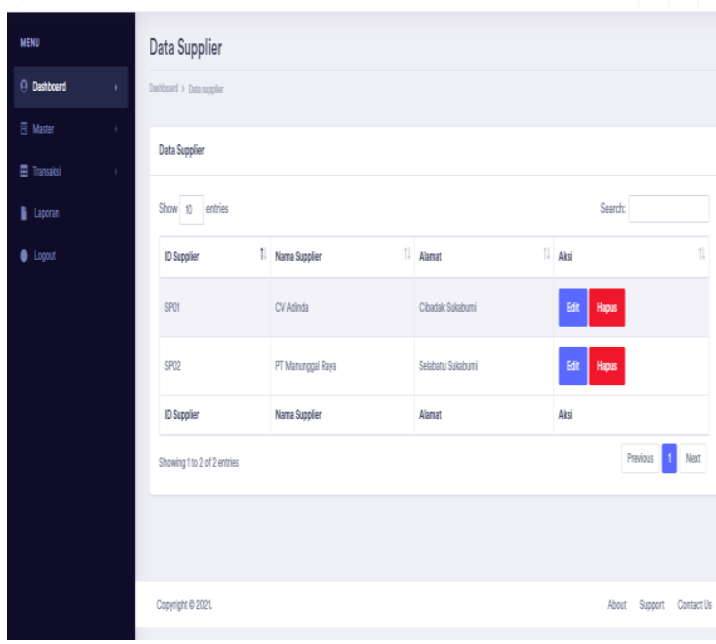

Sumber : Farlina, Susilawati, Koeswara (2021)

Gambar 6. Tampilan Input Supplier
3. Halaman Input Data Barang Masuk

Halaman input data barang masuk menyediakan input data barang masuk untuk bagian administrator. Bagian administrator bisa melakukan penghapusan data dan mencari data barang masuk dengan memasukan id barang masuk yang akan dicari.

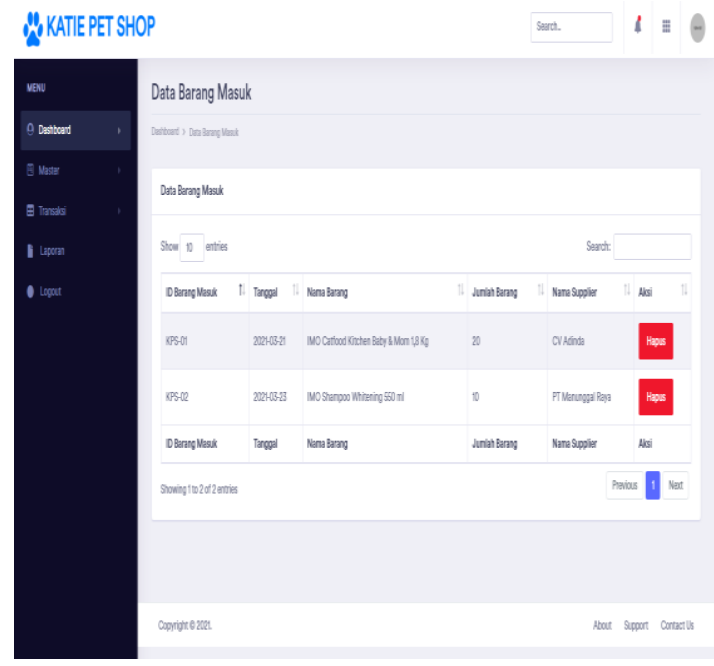

Sumber : Farlina, Susilawati, Koeswara (2021)

\section{Gambar 7. Tampilan Input Barang Masuk}

4. Halaman Input Data Barang Keluar

Halaman input data barang keluar menyediakan input data barang masuk untuk bagian administrator. Bagian administrator bisa melakukan penghapusan data dan mencari data barang kelaur dengan memasukan id barang masuk yang akan dicari.

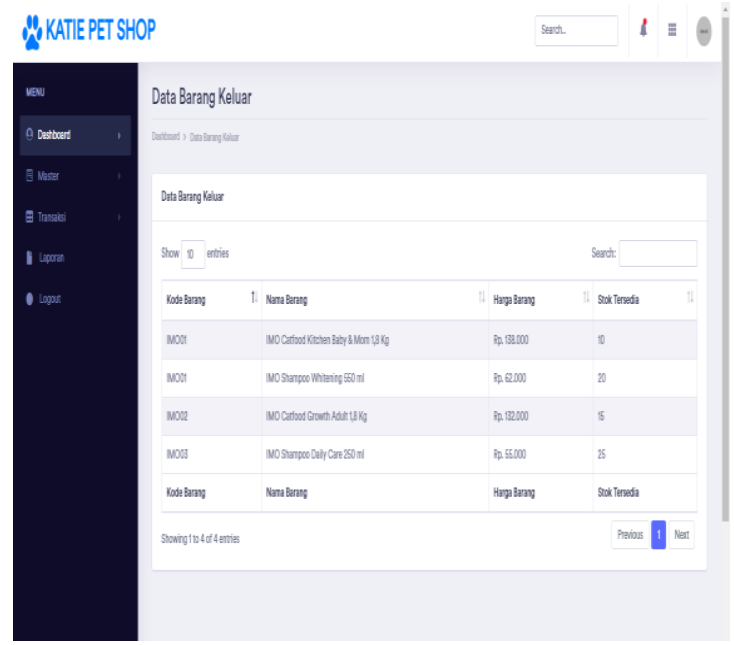

Sumber : Farlina, Susilawati, Koeswara (2021)

Gambar 8. Tampilan Input Barang Keluar 


\section{Kesimpulan}

Hasil dari uraian pembahasan yang telah disampaikan pada latar belakang, maka dapat ditarik kesimpulan sebagai berikut:

a. Dengan adanya website pengelolaan persediaan stok barang pada Toko Katie Pet Shop dapat mempermudah dan mempercepat proses dalam pencarian data barang masuk dan data barang keluar.

b. Memudahkan bagian administrator dalam mengelola data stok barang.

c. Mempermudah bagian administrator dalam membuat laporan, sehingga lebih cepat dan tepat.

d. Memudahkan bagian administrator dalam pemantauan stok barang.

\section{Referensi}

Abdullah, A. S., Setiawan, H., \& Ummi, N. (2013). Perancangan Sistem Informasi Berbasis Website Dengan Menerapkan Metode FAST (Framework For The Applications Of System Thinking). Jurnal Teknik Industri, 1(4), 358-367.

Cahyana, N. H., Yuwono, B., \& Asmoro, A. Y. (2012). Pengembangan Sistem Informasi Persediaan Barang Berbasis Web Di Pt . Putera Agung Setia. Pengembangan Sistem Informasi Persediaan Barang Berbasis Web Di Pt - Putera Agung Setia, 9(semnasIF), 252-258.

Elsera, M. (2018). Portal Publikasi Jurnal Karya Ilmiah Program Studi Sistem Informasi Ftk Universitas Harapan Berbasis Web Dengan Metode Fast (Framework for the Application of System Thinking). Buletin Utama Teknik, 14(1), 35-40.

Fatmawati, \& Munajat, J. (2018). Implementasi Model Waterfall Pada Sistem Informasi Persediaan Barang Berbasis Web (Studi Kasus: PT.Pamindo Tiga T). Jurnal Media Informatika Budidarma, 2(2), 1-9. https://doi.org/10.30865/mib.v2i2.559

Hakim, Z., Sakuroh, L., \& Awaludin, S. (2019). Sistem Informasi Persediaan Barang Berbasis Web Pada CV Telaga Berkat. Jurnal Sisfotek Global, 9(1), 6974.

Retrieved http://journal.stmikglobal.ac.id/index.php /sisfotek/article/view/214/225

Halim, R. M. N. (2020). Sistem Informasi Penjualan Pada TB Harmonis Menggunakan Metode FAST. Jurnal Sisfokom (Sistem Informasi Dan Komputer), 203. https://doi.org/10.32736/sisfokom.v9i2.8 68

Hasanudin, M. (2018). Rancang Dan Bangun Sistem Informasi Inventori Barang Berbasis Web (Studi Kasus PT. Nusantara Sejahtera Raya). Jurnal IKRA-ITH Informatika, 2(3), 24-37.

Junaidi, A., \& Sumirat, C. (2018). Aplikasi Persediaan Barang PT. CAD Solusindo Menggunakan Metode Waterfall. Jurnal Sisfokom (Sistem Informasi Dan Komputer), $\quad 7(1), \quad 28$. https://doi.org/10.32736/sisfokom.v7i1.2 80

Oktaviani, N., Widiarta, I. M., \& Nurlaily. (2019). Sistem Informasi Inventaris Barang Berbasis Web Pada Smp Negeri 1 Buer. Jurnal JINTEKS, 1(2), 160-168.

Priskila, R. (2018). Peracangan Sistem Informasi Persediaan Barang Pada Perusahaan Karya Cipta Buana Sentosa Berbasis Web Dengan Metode Extreme Programing. Journal of Computer Engineering System and Science, 3(2), 94-99.

Sari, A. O., \& Nuari, E. (2017). Rancang Bangun Sistem Informasi Persediaan Barang Berbasis Web Dengan Metode Fast (Framework For The Applications). Jurnal Pilar Nusa Mandiri, 13(2), 261266. 